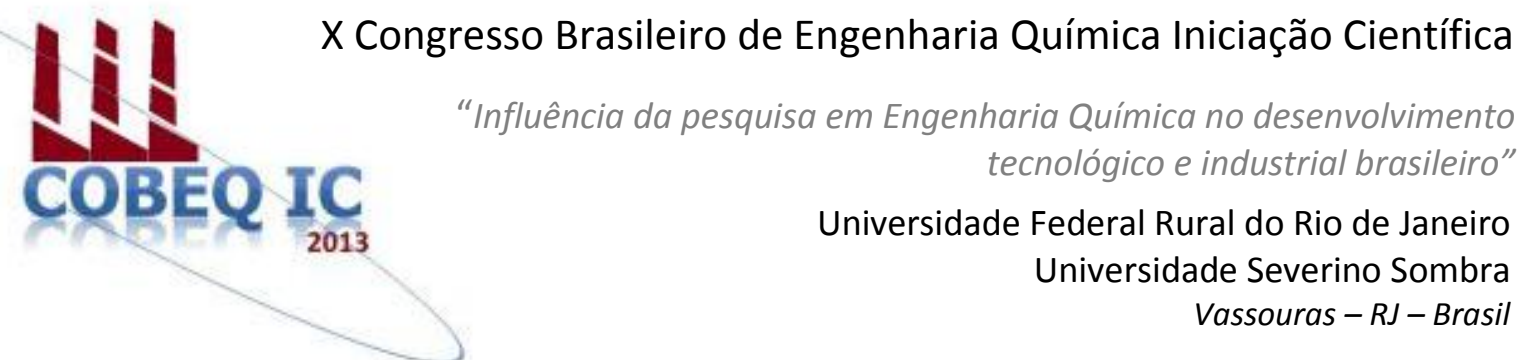

\title{
ESTUDO DA VIABILIDADE DE PRODUÇÃO DE AGUARDENTE A PARTIR DO SUCO DE LARANJA
}

\author{
FARIA ${ }^{1}$, B.V.R; FÉLIX ${ }^{1}$, L.G.S.; PEREIRA ${ }^{1}$, A.F.C.; PEREIRA ${ }^{1}$, L.P.; SOUZA ${ }^{1}$, M.; \\ SILVA ${ }^{1}$, W.C.R.; WALTER ${ }^{2}$, M.E. \\ ${ }^{1}$ Aluno do IET/UNIBH; \\ ${ }^{2}$ Professora do IET/UNIBH \\ Instituto de Engenharia e Tecnologia - Centro Universitário de Belo Horizonte \\ Endereço - UNIBH, Av. Professor Mário Werneck, 1685, Estoril, CEP 30.455-610, MG, \\ e-mail: barbara1806@ hotmail.com
}

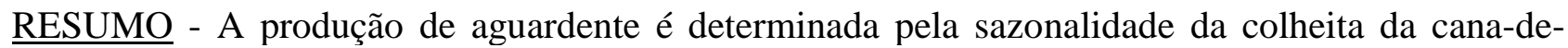
açúcar, pois na entressafra, a produtividade da destilaria reduz-se drasticamente e a planta opera abaixo de sua capacidade nominal. Porém, se fosse possível utilizar outra matéria-prima, cuja safra seja garantida durante todo o ano, esse problema seria resolvido. Nessa linha, investigou-se o desenvolvimento da fabricação de destilado do Citrus aurantium lumia, através do processo fermentativo do suco natural da laranja e da adição do agente fermentador da espécie Saccharomyces cerevisiae. Após a fermentação, inicia-se o processo de destilação do vinho com a separação estequiométrica de três fases do destilado: cabeça, coração e calda. Para obter-se dados analíticos suficientes para produção em grande escala, foram realizados testes pilotos, avaliando-se o grau brix, o teor de acidez, a temperatura ideal para fermentação e destilação, bem como a higienização do alambique e demais materiais utilizados, para assegurar a integridade da fabricação. Além disso, foram realizados testes de controle de qualidade avaliando teores de compostos orgânicos, grau alcoólico e outros elementos que podem influenciar, de alguma forma, o produto final. Nos primeiros ensaios realizados com a laranja da espécie Serra d'água, o grau alcoólico do produto foi insuficiente para ser classificado como aguardente. Realizou-se então, novos ensaios e foi possível obter um destilado de teor alcoólico de $44^{\circ} \mathrm{GL}$, com aparência límpida e incolor, aroma cítrico com a particularidade do destilado convencional, podendo ser considerada aguardente de acordo com as normas do Ministério da Agricultura, Pecuária e Abastecimento.

Palavras chave: mosto, fermentação, destilação, aguardente.

\section{INTRODUÇÃO}

Qualquer fruta que contenha níveis razoáveis de açúcar pode ser usada para produzir uma boa aguardente, sendo que esta terá sabores característicos da fruta utilizada como matéria-prima (CORAZZA et al., 2000).
Pela legislação, a aguardente é definida como a bebida com graduação alcoólica de 38 a $48 \%$ em volume, obtida através do rebaixamento do teor alcoólico do destilado alcoólico simples ou pela destilação do mosto fermentado, podendo ser obtida a partir de diversas matérias-primas vegetais (BRASIL, 2009). 
O processo de produção das aguardentes no interior do país é determinado pela sazonalidade da produção da cana-deaçúcar. Neste intervalo, os alambiques se tornam improdutivos, ocorrendo assim a interrupção da produção. Uma opção viável para os produtores que enfrentam esta dificuldade seria a inserção de outras matériasprimas para produção do produto no período de entressafra da cana (BARACHO, 2011).

A laranja é uma das frutas de matériaprima abundante, largamente difundida e de fácil produção em diferentes regiões. Trazida para o Brasil pelos portugueses, a laranja se tornou uma das frutas mais consumidas do país pelas suas ricas propriedades e valores nutricionais. É uma fruta pouco calórica, possuindo aproximadamente 40 calorias por 100 gramas (GURAK, 2010).

A Laranja Serra d'água foi introduzida no Brasil pelas primeiras expedições colonizadoras. É conhecida por ter um formato arredondado, uma casca lisa, fina e amarela. Sua polpa é suculenta, de sabor adocicado e levemente ácido, sendo assim muito indicada para a preparação de sucos. (LAROUSSE 1998).

O maior produtor de laranja do país é o estado de São Paulo sendo responsável por $79 \%$ de toda produção de acordo com dados do Instituto Brasileiro de Geografia e Estatística (IBGE, 2003).

Visando a otimização do processo produtivo devido à ampla produção da fruta ao longo do ano e o seu baixo custo de plantio, a produção da aguardente de laranja apresenta vantagens em relação à matéria prima convencional (a cana de açúcar) para a produção de cachaça, pelo fator principal do período de safra que não ocorre o ano todo.

Pensando na importância desse fruto e sua ampla utilização comercial, este trabalho propõe o desenvolvimento de um destilado, através da fermentação biológica do Citrus aurantium lumia (Laranja Serra D’água), utilizando como agente fermentador a espécie Saccharomyces cerevisiae, uma levedura muito empregada na indústria alimentícia e a avaliação da qualidade do produto fabricado.

\section{MATERIAL E MÉTODOS}

\section{Matéria-Prima}

A Laranja Serra d'água (Citrus aurantium lumia) foi à principal matéria-prima utilizada neste trabalho. Elas foram adquiridas na Central Empresa de Abastecimento de Minas Gerais S/A (Ceasa/Minas) localizada no município de Contagem, em Minas Gerais.

\section{Recepção e Seleção}

As frutas adquiridas foram transportadas até a Planta Piloto do UNI-BH (Campus Estoril), onde foram selecionadas para utilização apenas as laranjas que se encontravam em bom estado de conservação. Posteriormente, a matéria prima foi pesada, lavada, cortada, com auxílio de uma centrífuga, retirou-se o suco. Devido uma grande quantidade de partículas provenientes do bagaço da laranja, foi necessária uma filtragem em uma peneira fina.

\section{Teste Piloto}

Para obter dados analíticos suficientes para produção em grande escala, foram realizados testes pilotos, para assegurar a integridade da fabricação, os efeitos dos erros, das respostas, da falta de respostas e das diferenças nos diversos tipos de amostragem.

\section{Piloto 01}

Aos 26 dias do mês de agosto de 2013, foi realizado um piloto, a fim de testar a viabilidade de produção em grande escala.

O suco utilizado foi extraído de 55 laranjas, com rendimento de $2000 \mathrm{~mL}$, separados em um béquer. $\mathrm{O}$ rendimento foi baixo devido a alguns frutos estarem secos e outros com pouco suco a ser extraído. Em seguida com o auxílio do refratômetro foi medido o ${ }^{\circ}$ Brix e adicionado ao suco $22 \mathrm{~g}$ de fermento inoculo, posteriormente feita a correção do ${ }^{\circ}$ Brix com $170 \mathrm{~g}$ de sacarose.

\section{Piloto 02}

O segundo teste piloto foi realizado aos 09 dias do mês de setembro de 2013, com o intuito de se ter um maior volume de mosto fermentado.

O suco a ser utilizado na fermentação foi extraído de 120 laranjas, com rendimento 
aproximado de $6500 \mathrm{~mL} . \mathrm{O}{ }^{\circ}$ Brix apresentou um valor abaixo do necessário, então adicionou-se ao suco natural uma solução de $2500 \mathrm{~mL}$ de sacarose para corrigi-lo obtendo então $9000 \mathrm{~mL}$ de mostro então acrescentou-se $90 \mathrm{~g}$ de fermento ativado pela adição de $50 \mathrm{~mL}$ água morna e $90 \mathrm{~g}$ de açúcar.

A dorna de fermentação contendo o mosto foi lacrada com plástico filme e mantida em local seco, com iluminação indireta e sem agitação.

\section{Produção da Aguardente}

Após todos os métodos, manuseios e preparos realizados nos testes pilotos verificou-se quais seriam as variações para se produzir a aguardente em maior escala.

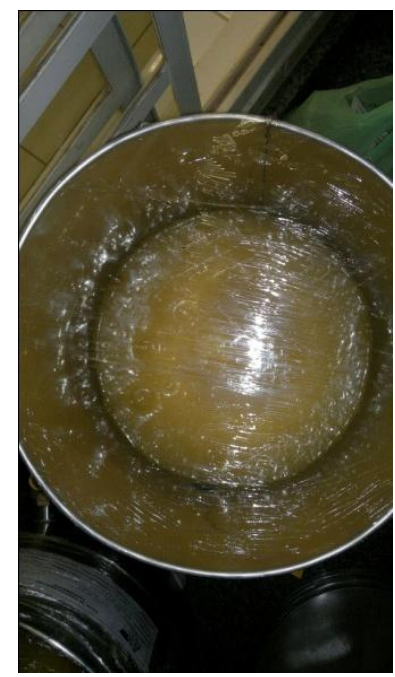

Figura 1 - Dornas de Fermentação FONTE - Arquivo Pessoal

O mosto foi preparado a partir dos 26 litros do suco extraído de 320 laranjas, foi adicionado $260 \mathrm{~g}$ de fermento biológico ativado pelo acréscimo de $50 \mathrm{~mL}$ água morna e $260 \mathrm{~g}$ de açúcar. Para adequar o ${ }^{\circ}$ Brix desejado adicionou-se uma solução de 3 litros de sacarose preparada a partir de uma parte do suco de laranja. Após adequação do mesmo o mosto foi separado em 3 dornas de fermentação FIG. 1.

\section{Destilação}

A fermentação alcoólica é a etapa mais crítica para a produção de aguardente. É nesta etapa que os cuidados são redobrados, pois a partir dela passa-se a trabalhar com microorganismos vivos (BARACHO, 2011).
A destilação foi feita em um alambique de cobre na Planta Piloto do UNI-BH campus Estoril (FIG. 2).

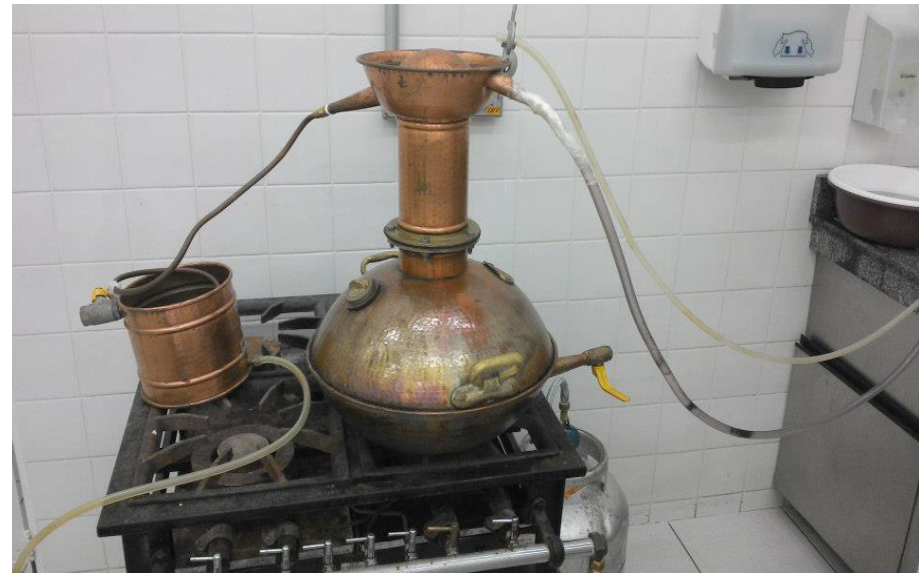

Figura 2 - Alambique utilizado na destilação. Fonte - Arquivo Pessoal

O Piloto 02 foi destilado no dia 11 de setembro de 2013 e a produção da aguardente no dia 19. O mosto foi filtrado através de uma peneira fina, para a separação do vinho dos sólidos insolúveis decantados.

\section{RESULTADOS E DISCUSSÃO}

Tabela 2 - Produção da Aguardente

\begin{tabular}{|c|c|c|c|c|c|}
\hline & $\begin{array}{c}\text { Volume } \\
(\mathrm{mL})\end{array}$ & $\begin{array}{c}\text { Brix } \\
\text { Inicial }\end{array}$ & $\begin{array}{c}\text { Fermento } \\
(\mathrm{g})\end{array}$ & $\begin{array}{c}\text { Açúcar }(\mathrm{g}) / \\
\text { Solução de } \\
\text { Sacarose }(\mathrm{mL})\end{array}$ & $\begin{array}{c}\text { Brix após } \\
\text { correção }\end{array}$ \\
\hline Piloto 1 & 2000 & 10,8 & 22,0 & Açúcar - 170g & 18,0 \\
\hline Piloto 2 & 6500 & 9,0 & 90,0 & Solução - 2500mL & 14,0 \\
\hline Aguardente & 26000 & 10,7 & 260,0 & Solução - 3000mL & 16,0 \\
\hline
\end{tabular}

A ocorrência de alguns erros no Piloto 1, como a ativação incorreta do fermento biológico, a falta de controle da temperatura, que, segundo Neves 2003, deveria ter sido mantida entre $28^{\circ} \mathrm{C}$ e $35^{\circ} \mathrm{C}$, o tempo de fermentação extrapolou o necessário na intenção de que o grau brix abaixasse, e a não disponibilização de oxigênio ao meio, já que as dornas foram mantidas em uma estufa com temperatura de $42^{\circ} \mathrm{C}$, levou a uma fermentação tumultuosa, e a não obtenção do volume necessário para destilar.

Observou-se que em todos os pilotos foi necessária a adição de sacarose para corrigir o grau brix, pois a laranja apesar de ser uma fruta adocicada não atinge um valor adequado para a fermentação biológica. 
Passando-se 18 horas (1080min) do início da fermentação da aguardente, aferiu-se que a conversão já havia atingido $75 \%$ do esperado. A conversão total foi atingida após 36 horas (2160min) de fermentação restando apenas sólidos insolúveis.

Durante a filtragem do mosto para a destilação, averiguou-se que somente $70 \%$ poderiam ser utilizados, parte esta denominada vinho e o restante não aproveitado apresentava uma característica gelatinosa e com um odor característico do inoculo, por este motivo, impossibilitou a sua filtração.

$\mathrm{Na}$ destilação do vinho foi separada a cabeça, o coração e a calda como recomendado. Sendo o coração a aguardente propriamente dita foi realizada a Cromatografia para determinar a sua qualidade química. A TAB. 3 apresenta os resultados analíticos encontrados no produto final.

Tabela 3 - Qualidade Química

\begin{tabular}{|l|c|c|c|c|}
\hline \multicolumn{1}{|c|}{ PARÂMETRO } & UNIDADE & REFERÊNCIAS & PILOTO 2 & AGUARDENTE \\
\hline Teor Alcoólico & ${ }^{\circ} \mathrm{GL} \mathrm{a} 20^{\circ} \mathrm{C}$ & $38-48$ & 45 & 44 \\
\hline $\begin{array}{l}\text { Alcoóis Superiores } \\
\text { Totais }\end{array}$ & $\mathrm{mg} / 100 \mathrm{~mL}$ & $\leq 360$ & 276 & 350 \\
\hline Álcool n-propílico & $\mathrm{mg} / 100 \mathrm{~mL}$ & - & 44 & 33 \\
\hline Álcool Isobutlico & $\mathrm{mg} / 100 \mathrm{~mL}$ & - & 80 & 118 \\
\hline Álcool Isoamillico & $\mathrm{mg} / 100 \mathrm{~mL}$ & - & 152 & 200 \\
\hline Acetato de Etila & $\mathrm{mg} / 100 \mathrm{~mL}$ & $\leq 200$ & 11 & 23 \\
\hline Aldeído Acético & $\mathrm{mg} / 100 \mathrm{~mL}$ & - & 11 & 23 \\
\hline $\begin{array}{l}\text { Componentes } \\
\text { Voláteis Totais }\end{array}$ & $\mathrm{mg} / 100 \mathrm{~mL}$ & $200-650$ & 299 & 397 \\
\hline Cobre & $\mathrm{mg} / 1000 \mathrm{~mL}$ & $\leq 5$ & - & 4,8 \\
\hline
\end{tabular}

Além destes dados, também foi obtido um cromatograma que tem por finalidade mostrar os picos específicos de cada componente. A FIG. 3 mostra o cromatograma referente à aguardente produzida a partir do suco de laranja.

Cada pico corresponde à presença do grupo funcional no produto final. As correspondências dos picos foram:

Pico 1 - Acetaldeído;

Pico 2 - Acetato de Etila;

Pico 3 - Álcool n-Propílico;

Pico 4 - Álcool Isobutílico;

Pico 5 - Álcool Isoamílico.

Não foi detectado pelo cromatograma o pico referente ao metanol, isso significa que durante a destilação a cabeça e o coração foram separados corretamente. Um alto teor de metanol contaminaria a aguardente e esta estaria imprópria para o consumo.

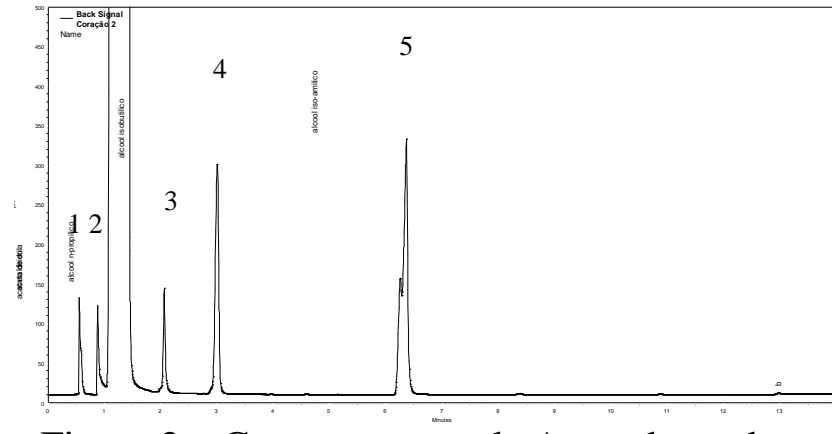

Figura 3 - Cromatograma da Aguardente de Laranja

Pode-se observar que com os ensaios realizados, foi possível obter dois destilados com aparência límpida e incolor e aroma cítrico, um com teor alcoólico de $45^{\circ} \mathrm{GL}$ e outro com $44^{\circ} \mathrm{GL}$. Todos os outros parâmetros ficaram dentro do permitido, sendo assim o destilado pode ser considerada uma aguardente de acordo com as normas do MAPA.

A partir dos parâmetros operacionais do piloto 2, é possível produzir aguardente utilizando-se como matéria-prima o suco de laranja.

Os principais resíduos obtidos durante a produção foram a casca, o bagaço do fruto e o sólido suspenso retido na filtração do mosto. Todos eles podem ser reaproveitados, por exemplo, como aditivos na produção de ração animal.

\section{CONCLUSÃO}

Foi possível o desenvolvimento da aguardente a partir da matéria-prima proposta, dando às destilarias uma alternativa de produção trazendo uma nova opção para o mercado alvo.

Avaliando todo o projeto $\mathrm{e}$ os resultados obtidos, constatou-se a viabilidade do processo em escala laboratorial, sendo necessária uma avaliação das condições em uma produção industrial.

Como a aguardente é o desenvolvimento um novo produto no mercado, é preciso conhecer sua aceitação comercial. Com isso posteriormente será necessário uma análise sensorial para responder a três importantes questões determinísticas para o sucesso de um novo produto: descritiva, que revela quais características sensoriais são percebidas pelos 
entrevistados, discriminativa, que mostra se o consumidor consegue sentir diferença entre seu produto e um outro similar, e preferencial, onde se tem o conhecimento da aceitação e satisfação daquele novo desenvolvimento. Seu resultado deve ser expresso de forma específica em meios estatísticos concluindo assim a viabilidade do produto.

A produção de uma nova aguardente com uma matéria-prima diferenciada, como proposta neste estudo, requer todo esse trabalho de reconhecimento e mapeamento das características produzidas, a fim de satisfazer e atender as exigências de público alvo.

\section{REFERÊNCIAS}

BARACHO, Rafael de Albuquerque. Estudo da produção piloto de aguardente de laranja em escala laboratorial. Universidade Federal da Paraíba. Bananeiras, PB, 2011.

BRASIL. Ministério da Agricultura, Pecuária e Abastecimento. Decreto $\mathrm{n}^{\circ}$ 6.871, de 4 de junho de 2009. Regulamenta a Lei no 8.918, de 14 de julho de 1994, que dispõe sobre a padronização, a classificação, o registro, a inspeção, a produção e a fiscalização de bebidas. Brasília, art. 84, inciso IV, 2009. Seção 1.

CORAZZA, M. L., RODRIGUES, D. G., NOZAKI, J. Preparação e Caracterização do Vinho de Laranja; Dep. de Química. Universidade Estadual de Maringá, 26/01/2000.

GURAK, P. D.; BORTOLINI, F. Produção e aceitabilidade de fermentado de laranja no alto Uruguai catarinense. Revista Brasileira de Tecnologia Agroindustrial. Universidade Tecnológica Federal do Paraná (UTFPR), Campus Ponta Grossa, 2010.

IBGE, Instituto Brasileiro de Geografia e Estatística. Pesquisa dados de 2003, Produção Agrícola Municipal.

LAROUSSE, GRANDE ENCICLOPÉDIA LAROUSSE CULTURAL. Nova Cultural Ltda, 1998. ISBN: 85-13-00868-4, pag 105.
NEVES, L. C. M. Obtenção da enzima glicose 6-fosfato desidrogenase utilizando 'Saccharomyces cerevisiae' W303-181. Dissertação de mestrado (Tecnologia de Fermentações) - Faculdade de Ciências Farmacêuticas, São Paulo, 2003. 